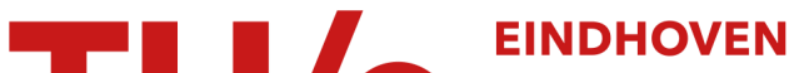 \\ UNIVERSITY OF \\ TECHNOLOGY
}

\section{Hybrid-excited variable reluctance machines}

Citation for published version (APA):

Lomonova, E. A., Tang, Y., \& Paulides, J. J. H. (2015). Hybrid-excited variable reluctance machines. In H. B. Ertan (Ed.), 2015 International Aegean Conference on Electrical Machines and Power Electronics, 2-4 September 2015, Side, Turkey: proceedings Institute of Electrical and Electronics Engineers. https://doi.org/10.1109/OPTIM.2015.7426741

DOI:

10.1109/OPTIM.2015.7426741

Document status and date:

Published: 01/01/2015

\section{Document Version:}

Accepted manuscript including changes made at the peer-review stage

\section{Please check the document version of this publication:}

- A submitted manuscript is the version of the article upon submission and before peer-review. There can be important differences between the submitted version and the official published version of record. People interested in the research are advised to contact the author for the final version of the publication, or visit the $\mathrm{DOI}$ to the publisher's website.

- The final author version and the galley proof are versions of the publication after peer review.

- The final published version features the final layout of the paper including the volume, issue and page numbers.

Link to publication

\section{General rights}

Copyright and moral rights for the publications made accessible in the public portal are retained by the authors and/or other copyright owners and it is a condition of accessing publications that users recognise and abide by the legal requirements associated with these rights.

- Users may download and print one copy of any publication from the public portal for the purpose of private study or research.

- You may not further distribute the material or use it for any profit-making activity or commercial gain

- You may freely distribute the URL identifying the publication in the public portal.

If the publication is distributed under the terms of Article $25 \mathrm{fa}$ of the Dutch Copyright Act, indicated by the "Taverne" license above, please follow below link for the End User Agreement:

www.tue.nl/taverne

Take down policy

If you believe that this document breaches copyright please contact us at:

openaccess@tue.nl

providing details and we will investigate your claim. 


\title{
Hybrid-Excited Variable Reluctance Machines
}

\author{
E.A. Lomonova ${ }^{1}$, Senior Member, IEEE, Y. Tang ${ }^{1}$, Member IEEE, J.J.H. Paulides ${ }^{1}$, Senior Member, \\ IEEE
}

Eindhoven University of Technology, Den Dolech 2, 5612 AZ, The Netherlands

\section{INTRODUCTION}

Hybrid excited variable reluctance machines (HEVRMs), including the so-called flux-switching machines and doublesalient machines, are double-salient structured brushless machines with both the commutation windings and auxiliary magnetic excitation sources, i.e. permanent magnet or DC field windings, in the stator. The earliest introduction of this class of machines can be traced back to 1946, when Walker summarized a series of alternators that employ salient poles in the rotor and two sets of coils, namely armature coils and field coils, in the stator [1]. According to the polarity of the armature flux linkage, these alternators were classified as homopolar inductor alternators and heterpolar alternators. Despite of different terminologies, this paper presents the basic concepts and examples of both types of DC excited HEVRMs.

Inspired by Walker, in 1955 Rauch and Johnson introduced a single-phase two-rotor-tooth alternator, termed flux-switch alternators, which adopted a similar concept to the type I-III alternators in [1], however, replaced the field-coil with two permanent magnets [2]. This was the first available publication on flux-switching permanent magnet machines. In 1999, Pollock used the name flux-switching motor for a single-phase two-rotor-tooth VRM that has a similar structure to the aforementioned I-III type alternator. Since then, increasing attention has been paid to these types of machines, which are commonly recognized as flux-switching machines [3-6], although alternative terms such as switched-flux machine $[7,8]$ and flux-reversal machine $[9,10]$ occasionally seen in literature.

The evolvement of the other type of HEVRMs followed a different trajectory. In 1989, Philips presented the potential benefits of pre-magnetization for switched reluctance machines using a full-pitch field winding [11]. This concept was later explored by Liang, Liao, and Lipo from a different perspective[12]. These authors further presented the possibility of using permanent magnets instead of field coils for the pre-magnetization and proposed a permanent magnet motor with doubly salient structure, namely double-salient permanent magnet motor [13]. Since then, a significant study on this type of machines has been carried out and published, in which alternative terms such as switched reluctance machines with DC/PM assisted excitation [14-16] and variable flux reluctance machines [17] were used.

Design and control of HEVRM require a thorough understanding of the torque production mechanism of this machine. The characteristics of FSMs are often considered comparable to that of DC machine (DCM), wound-field synchronous machines (WFSM), or brushless AC/DC machines (BLAC/DCM).
In [18], the torque of a single-phase DCEFSM was calculated using a similar equation to that used for DC machines. In [1921] three-phase FSMs were analyzed as conventional BLACMs. In [21] the dq- reference frame was adopted to calculate the torque of a FSPMM. However, the airgap magnetic field of DCEFSM shows a pulsating behavior, which is completely different from that in DCM or SM and more similar to that in SRMs. In contrast, DSMs are usually considered as a switched reluctance machines with a prebiased excitation field produced by PM or DC coils, due to their unipolar armature flux linkage.

However, [22] proposed a three-phase DSM topology with 6 stator slots and 5 rotor teeth, which acquires a bipolar phase flux linkage. While the boundary between these two types of HEVRMs becomes vague, a question on the nature of torque production in this class of machines is raised: is it Lorentz torque or reluctance/cogging torque? To answer this question, this paper presents a study on the energy conversion in single-phase HEVRMs, which highlights the factors that influence the armature flux linkage and torque production. The characteristics of this class of machines are thus revealed in comparison with conventional brushed DC machines, wound-field synchronous machines, brushless AC/DC machines and switched reluctance machines.

\section{OPERATING PRINCIPLE}

Figure $1(a, b)$ shows the structures of a single-phase fluxswitching permanent magnet machine (FSPMM) and a single-phase double salient permanent magnet machine (DSPMM).

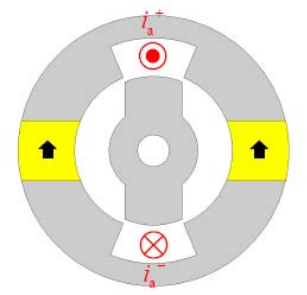

(a) FSPMM

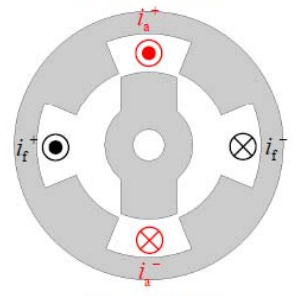

(c) DCEFSM

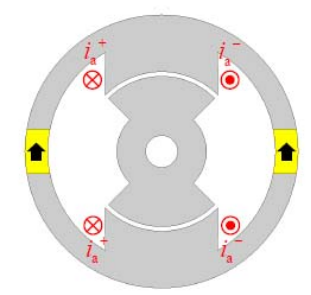

(b) DSPMM

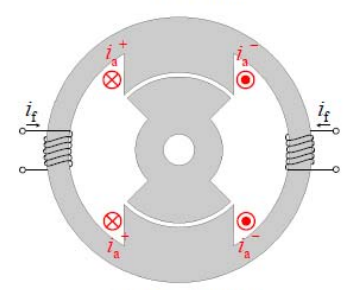

(d) DCEDSM
Figure 1: Single-phase hybrid excited variable reluctance machines: a)fluxswitching permanent magnet machine (FSPMM); b) double-salient permanent magnet machine (DSPMM); c) DC-excited flux-switching machine (DCEFSM); d) DC-excited double-salient machine (DCEDSM). 
In the FSPMM, each magnet is placed between two conductors of an armature coil, while in the DSPMM the magnets are placed on the two sides of an armature coil. Figure $1(c, d)$ shows structures of a single-phase DC excited flux-switching machine (DCEFSM) and a single-phase DC excited double salient machine(DCEDSM). In the DCEFSM the DC-field coil is partially overlapped with the armature coil, while in the DCEDSM the two armature coils are fully coupled with the DC field coil.

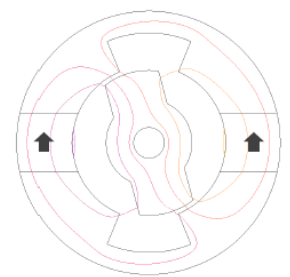

(a) Position A: $\theta=\theta_{1}, i_{\mathrm{a}}=0$

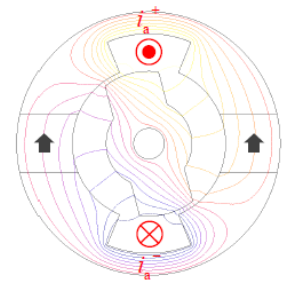

(c) Position A: $\theta=\theta_{1}, i_{\mathrm{a}}>0$

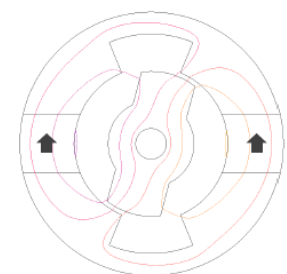

(b) Position B: $\theta=-\theta_{1}, i_{\mathrm{a}}=0$

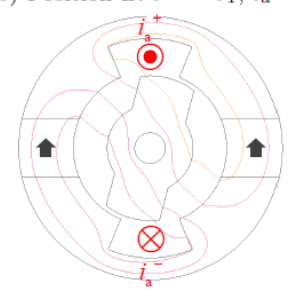

(d) Position B: $\theta=-\theta_{1}, i_{\mathrm{a}}>0$
Figure 2: Magnetic equipotential contour of a single-phase DC-excited fluxswitching machine without/with armature current $i_{a}$.

Due to the presence of permanent magnets or DC-field coils in these machines, torque can be generated instantly and locally when a rotor tooth is not in alignment with an adjacent stator tooth, even in absence of the armature current. The nature of this torque is the interaction between the salient rotor and the permanent magnets or DC current, namely cogging torque or reluctance torque, respectively. However, without armature currents the mean torque of these machines in a revolution of the rotor's rotation is zero. The reason is demonstrated in Fig. 2. For every rotor position A: $\theta=\theta_{l}$, there is a position $\mathrm{B}: \theta=-\theta_{1}$ that is symmetric with respect to the center of stator slots. The magnetic fields in the machine with these two rotor positions are also symmetric, as shown in Fig. $2(a, b)$. Hence, the torque exerted on the rotor at position $\mathrm{A}$ is equal and opposite to that at position $\mathrm{B}$, resulting in zero mean torque in a revolution of rotor's rotation. Meanwhile, if an armature current is introduced and commutated in such a manner that it intensifies the field when the rotor is at position $\mathrm{A}$ and weakens the field when the rotor is at position $B$, the absolute value of the torque at position $\mathrm{A}$ will be higher than that at position $\mathrm{B}$, shown in Fig. 2 (c, d). By this means, a positive mean torque is obtained. This principle of torque production is universal for both FSM and DSM. However, due to different placements of magnetic excitation sources and armature coils, the flux linkages of an armature coil in these two types of machines are distinct, leading to different machine performances. To reveal this difference, the principles of energy conversion in these two types of machines are investigated.

\section{FLUX LINKAGES AND INDUCTANCES}

In a single-phase HEVRM, the flux, $\psi_{a}$, linked by an armature coil consists of two components: the flux created by the armature current, named as the armature flux, and the flux created by the magnetic excitation source, termed as the excitation flux. Thus, for a single-phase HEVRM with PM excitation, such as FSPMM and DSPMM, the flux linkage of an armature coil, $\psi_{a}$, can thus be expressed as:

$$
\psi_{a}=\psi_{a a}+\psi_{m}=L_{a a} i_{a}+\psi_{m}
$$

where $\psi_{a a}$ represents the linkage of flux created by the armature current, $i_{a}$, through the self-inductance of the armature coil, $L_{a a}$, and $\psi_{m}$ is the linkage of flux created by permanent magnets in the machine.

Similarly, for a single-phase HEVRM with DC excitation, such as DCEFSM and DCEDSM, the flux linkage of an armature coil, $\psi_{a}$, can be expressed as:

$$
\psi_{a}=\psi_{a a}+\psi_{a f}=L_{a a} i_{a}+M_{a f} i_{m}
$$

where $\psi_{a f}$ represents the linkage of flux created by the DC field current if through the mutual inductance between the armature and field coils, $M_{a f}$. In these equations $L_{a a}, M_{a f}$ and $\psi_{m}$ are variant with respect to the rotor position.

Figure 3(a-d) shows the cross-sections of a single-phase DCEFSM with different rotor positions during an electrical period. In this machine, the maximum values of armature self-inductance, $L_{a a_{-} \max }$, and mutual inductance, $M_{a f_{\text {max }} \text {, are }}$ both reached when the rotor teeth are fully aligned with the stator teeth, i.e. $\theta=45^{\circ}$ and $135^{\circ}$. In contrast, the minimum values $L_{a a \text { min }}$ and $M_{a f \text { min }}$ are reached when the rotor teeth are fully misaligned with the stator teeth, i.e. $\theta=0^{\circ}$ and $90^{\circ}$ where $M_{a f \text { min }}$ decreases to zero as no flux created by the field current is linked by Coil A at these two positions. Furthermore, the polarity of the excitation flux $\psi_{a f}$ is inverted when $\theta>90^{\circ}$, therefore the mutual inductance is presented as negative at these rotor positions. These presumed characteristics of inductances and flux linkages of the singlephase DCEFSM can also be used to describe a single-phase FSPMM, in which the excitation flux linkage, $\psi_{m}$, varies in a similar manner to $\psi_{a f}$ with respect to the rotor position. Figure 5a shows the FEA result of variation of inductances and flux linkages of single-phase FSMs during an electrical period of rotor's rotation, which confirms the aforementioned presumptions.

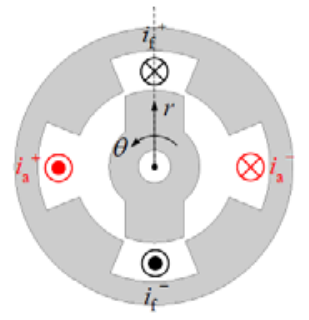

(a) $\theta=0^{\circ}$

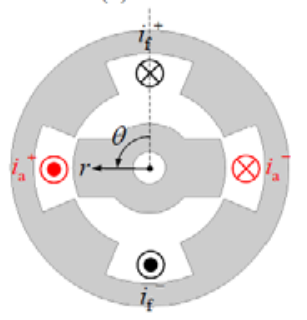

(c) $\theta=90^{\circ}$

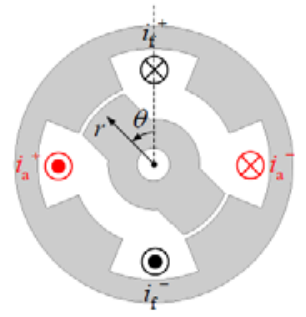

(b) $\theta=45^{\circ}$

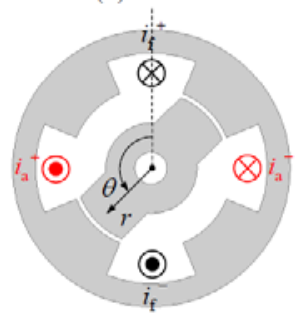

(d) $\theta=135^{\circ}$
Figure 3: Cross-sections of single-phase DC-excited flux-switching machine (DCEFSM) with different rotor positions. 


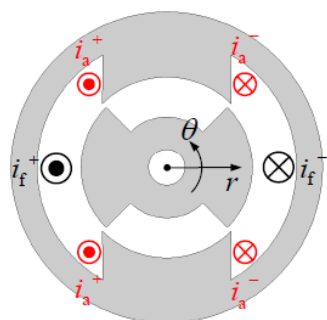

(a) $\theta=0^{\circ}$

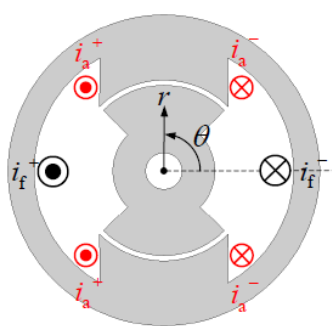

(b) $\theta=90^{\circ}$
Figure 4: Cross-sections of single-phase DC excited double-salient machine (DCEDSM) with different rotor positions.

Figure $4(\mathrm{a}, \mathrm{b})$ shows the cross-sections of a single-phase DCEDSM with different rotor positions within an electrical period. In this machine, the armature coil is fully coupled with the field coil, hence the mutual inductance between the two coils, $M_{a f}$, is proportional to the self-inductance of the armature coil $L_{a a}$. The ratio between these two inductances is equal to the ratio of the number of turns of the field winding, $N_{f}$, to that of the armature winding, $N_{a}$, i.e.:

$$
\frac{M_{a f}}{L_{a a}}=\frac{N_{f}}{N_{a}}
$$

The maximum values of these two inductances are both reached when the rotor teeth are fully aligned with the stator teeth, i.e. $\theta=90^{\circ}$, while the minimum value is reached when the rotor teeth are fully misaligned with the stator teeth, i.e. $\theta$ $=0^{\circ}$ and $180^{\circ}$. Using equation (3), an equation (2) for DCEDSM can be rewritten as:

$$
\psi_{a}=L_{a a}\left(i_{a}+\frac{N_{f}}{N_{a}} i_{f}\right)
$$

In this machine, the excitation flux linked by an armature coil always keeps the same polarity, this characteristic can also be observed from DSPMMs. Figure 5b shows the FEA result of variation of inductances and flux linkages of singlephase DSMs during an electrical period of rotor's rotation, which confirms the aforementioned presumptions. Based on the understanding of variation of inductances and flux, energy conversion mechanism of these single-phase HEVRMs with different switching strategies is further explored.

\section{ENERGY CONVERSION IN FLUX-SWITCHING MACHINES}

\section{A. Half-period current conduction}

The switching strategy so-called half-period current conduction is similar to that used for SRM. In this strategy, the armature current is conducted when the rotor rotates from an unaligned position towards the next aligned position and switched off before the rotor reaches that aligned position. For FSMs, due to the bipolar flux linkage created by permanent magnets or the field current, the armature current should be reversely conducted when $\theta>90^{\circ}$ so that the magnetic field is intensified in a different direction. Figure $6 \mathrm{a}$ shows the idealized waveform of the armature current using this switching strategy.

The process of energy/co-energy conversion is presented in Fig. 6b. The red dashed lines indicate the armature flux linkage created by the DC-field current $I_{f}$, in which the slope of each line corresponds to the mutual inductance $M_{a f}$ with different rotor positions.

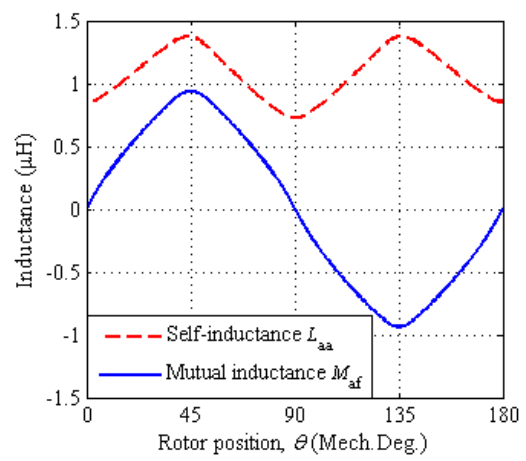

(a)

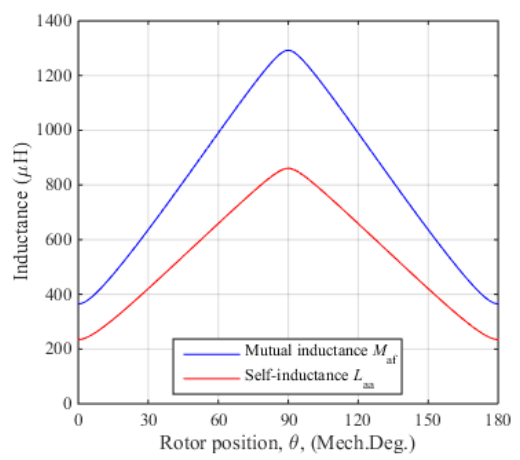

(b)

Figure 5: Self- and mutual inductance of the armature winding of a) the single-phase DC-excited flux-switching machine (DCEFSM) and b) DCexcited double-salient machine (DCEDSM).

Lines inside ABCD-area and EFGH-area show the additional flux-linkage component created by the armature current, while the slope of each line corresponds to the selfinductance $L_{a a}$ with different rotor positions. The current-flux linkage $(i-\psi)$ loop is thus derived, shown in Fig. 6c. When the rotor position changes from A: $\theta=0^{\circ}$ to $\mathrm{B}: \theta=45^{\circ}$, the armature current is imposed at $I_{a}$, hence the armature flux linkage increases with the increasing self- and mutual inductances $L_{a a}$ and $M_{a f}$. When the rotor reaches the aligned position $\mathrm{B}$, the armature current is switched off, thus the armature reaction disappears. From $\mathrm{C}$ to $\mathrm{D}$, the armature flux linkage contains only the component created by the field current till a reversely conducted current is switched on at E. Then a similar procedure of energy conversion is repeated in the third quadrant. The part of energy converted from the electromagnetic form to the mechanical one can be calculated as:

$$
w_{\text {mech }}=w_{\text {elec }}-\left(W_{\psi u}-W_{\psi \mathrm{a}}\right)=S_{A B Q P}-\left(S_{B Q C}-S_{A P D}\right)=S_{A B C D},
$$

where $w_{\text {mech }}$ is the mechanical work done by the electromagnetic torque, $w_{\text {elec }}$ is the electrical work done by the armature current, $W_{\psi u}$, and $W_{\psi \mathrm{a}}$ are the magnetic energy of the armature winding with unaligned and aligned rotor positions, respectively. Apparently, this mechanical energy, $w_{\text {mech }}$, is corresponding to the area enclosed in the $(i-\psi)-$ loops $\mathrm{ABCD}$ and $\mathrm{EFGH}$, which can be calculated as the change of co-energy $\Delta W^{\prime}{ }_{\Phi}$ during one electrical period. From Fig. $6 \mathrm{c}$ it can be seen that 


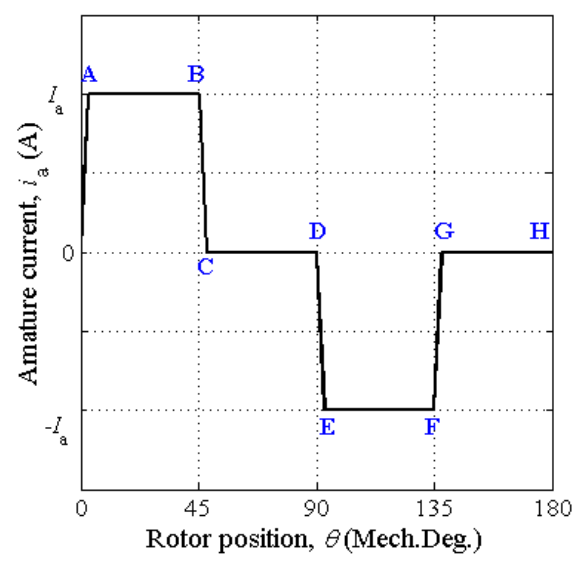

(a)

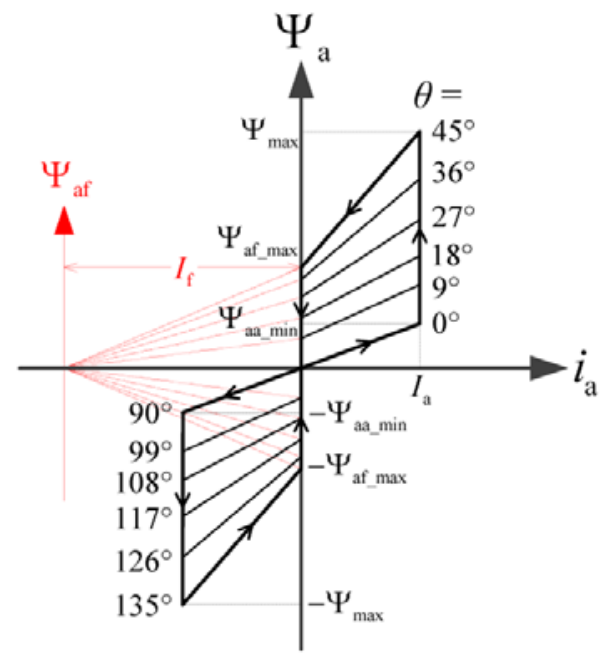

(b)

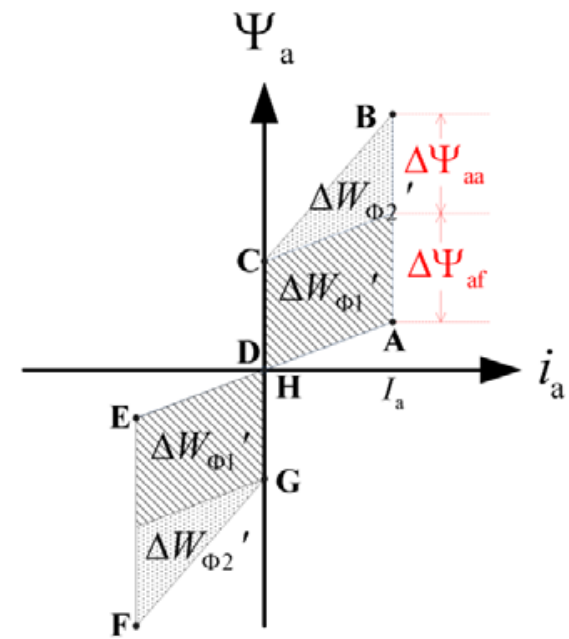

(c)

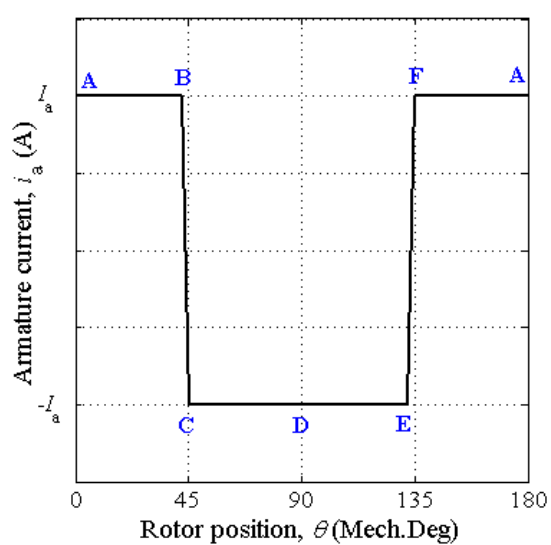

(d)

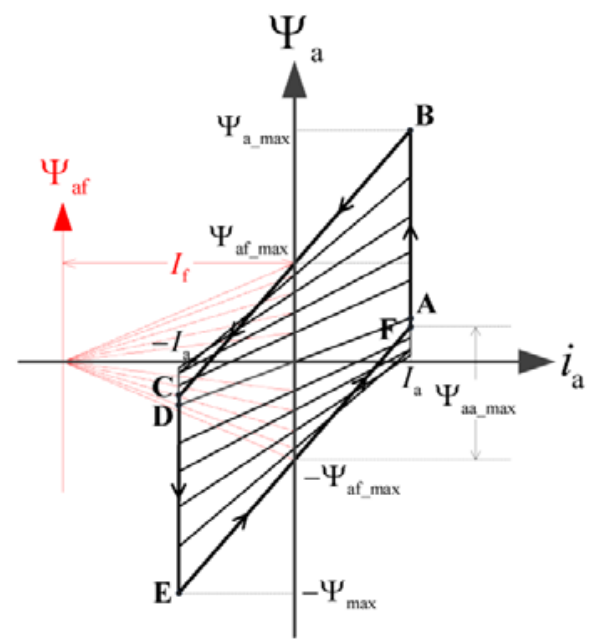

(e)

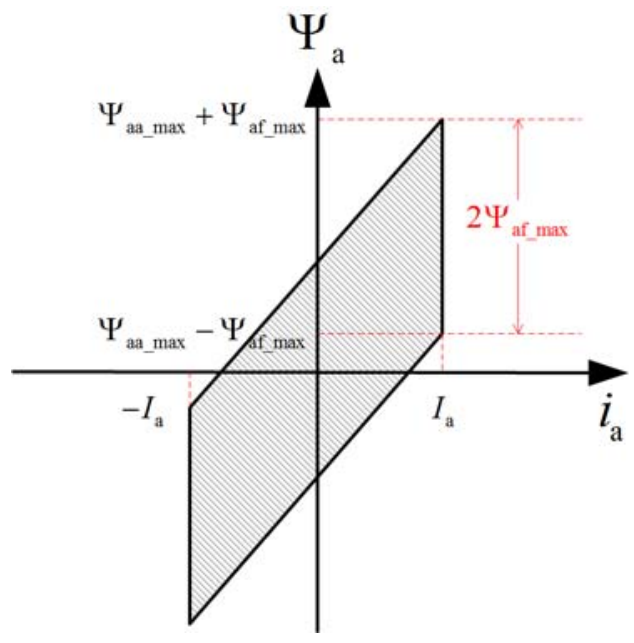

(f)

Figure 6: Energy/ co-energy of the single-phase DCEFSM with half-period current conduction and with full-period current conduction, respectively: a) idealized waveform of the armature current; b) energy/co-energy conversion process; c) current flux-linkage loop; d) idealized waveform of the armature current; e) energy/co-energy conversion process; f) current-flux linkage loop. 


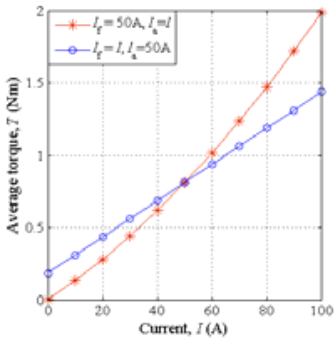

(a)

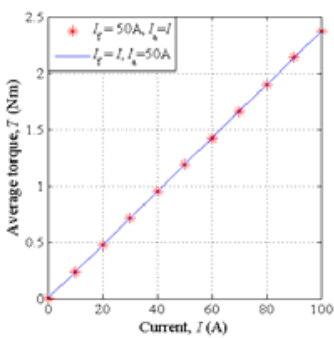

(c)

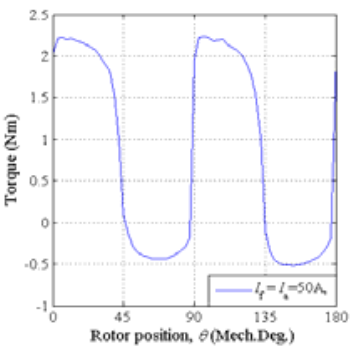

(b)

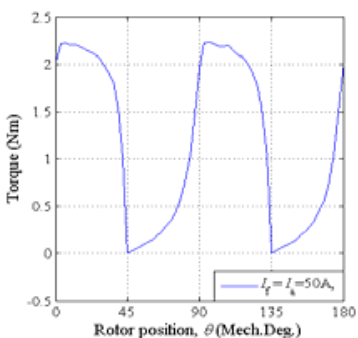

(d)
Figure 7: FEA results of the torque production in single-phase dc-excited flux-switching machine with half-period current conduction (S1)and fullperiod current conduction (S2): a) S1: mean torque vs. armature current / Field current; b) S1: torque vs. rotor position $\left(I_{a}=I_{f}=50 \mathrm{~A}\right)$; c) S2: mean torque vs. armature current /field current; d) S2: torque vs. rotor position $\left(I_{a}=I_{f}=50 \mathrm{~A}\right)$.

the area of each loop can be divided into two parts: a parallelogram (AOCD) and a triangle (OBC). The length of the side $\mathrm{AO}$ indicates the difference in the armature flux linkage, $\Delta \psi_{a f}$, created by the field current between the aligned and unaligned rotor positions. While, the length of the side $\mathrm{OB}$ indicates that difference in the armature flux linkage, $\Delta \psi_{a a}$, created by the armature current.

Hence, the total area $\Delta W^{\prime}{ }_{\Phi}$ can be calculated as:

$$
\Delta W_{\Phi}^{\prime}=2\left(\Delta W_{\Phi 1}^{\prime}+\Delta W_{\Phi 2}^{\prime}\right)=2 \Delta \psi_{a f} I_{a}+\Delta \psi_{a a},(6)
$$

where:

$$
\begin{aligned}
& \Delta \psi_{a f}=\left(M_{a f_{-} \max }-M_{a f_{-} \min }\right) I_{f}, \\
& \Delta \psi_{a a}=\left(L_{a a \_ \text {max }}-L_{a a_{\_} \min }\right) I_{a},
\end{aligned}
$$

while $L_{a a_{-} \max }$ and $M_{a f \max }$ are the self- and mutual inductances when rotor teeth are fully aligned with stator teeth, $L_{a a \text { min }}$ and $M_{a f \min }$ are the self- and mutual inductances when the stator and rotor teeth are unaligned. From Fig. 6 it can be seen that: $M_{a f \min }=0$. Therefore, with this switching strategy the mean torque can be calculated as:

$$
\begin{aligned}
& \bar{T}=\frac{\Delta W_{\Phi}^{\prime}}{\pi}=\frac{2}{\pi} M_{a f \_m a x} I_{f} I_{a}+\frac{1}{\pi}\left(L_{a a \_m a x}-\right. \\
& \left.L_{a a \_m i n}\right) I_{a}^{2},
\end{aligned}
$$

where $\pi$ is the mechanical angle of one electrical period of this two-rotor-tooth DCEFSM. For FSPMM, the peak excitation flux linkage, $\Delta \psi_{a f_{-} \max }$, is denoted as $\Delta \psi_{m_{-} \max }$, hence the mean torque of a single-phase FSPMM with halfperiod current conduction can be expressed as:

$$
\bar{T}=\frac{2}{\pi} \Delta \psi_{m \_ \text {max }} I_{a}+\frac{1}{\pi}\left(L_{a a_{-} \max }-L_{a a_{-} \min }\right) I_{a}^{2},
$$

Two torque components can be found in the torque expressions of equations $(9,10)$. The first torque component is proportional to the product of the armature current, $I_{a}$, and the peak excitation flux linkage, $\psi_{a f \max }$, which is comparable to the Lorentz torque generated in a DC or synchronous machine. The second torque component is proportional to the square of armature current and the difference between the self-inductances of the armature winding with aligned and unaligned rotor positions, which is similar to the reluctance torque generated in an SRM.

The FEA results of the torque production in a singlephase two-rotor-tooth DCEFSM with this half-period current conduction are presented in Fig. 7(a, b). It can be seen in Fig. 7a that when the field current is constant, e.g. $I_{f}$ $=50 \mathrm{~A}$, the mean torque shows a second order relation with the peak value of the armature current, $I_{a}$, while when the armature current is constant, the relation between the mean torque and the field current is fairly linear. Hence, the relation between the mean torque and the armature and field currents presented in (9) is validated.

However, this switching strategy is usually not optimal for the torque production. After the rotor crosses the aligned position, the field current is still creating flux despite of zero armature current. This ongoing field current generates a negative torque, as seen in (9), which reduces the mean torque.

\section{B. Full-period current conduction}

The aforementioned negative torque can be reduced by reverting the armature current right after the rotor crosses the aligned position, thus increasing the mean torque. The idealized waveform of the armature current using this switching strategy is shown in Fig. 6d. The process of energy/co-energy conversion with this switching strategy is shown in Fig. 6e. When the rotor reaches the aligned position B: $\theta=45^{\circ}$, the armature current changes from $i_{a}$ to $-i_{a}$, hence the total flux linkage of the armature winding decreases from $\Psi_{a_{-} \max }$ to $-\Psi_{a_{-} \min }$, in which:

$$
\begin{aligned}
& \psi_{a \_ \text {max }}=\psi_{a a_{-} \max }+\psi_{a f_{-} \max }, \\
& \psi_{a_{-} \min }=\psi_{a a_{-} \min }+\psi_{a f_{-} \min } .
\end{aligned}
$$

The armature current is then imposed at $-i_{\mathrm{a}}$ till the rotor crosses the next aligned position $\mathrm{E}: \theta=135^{\circ}$, in the meantime the flux linkage of the armature winding increases towards the maximum value with an opposite polarity, i.e. $-\Psi_{a-\max }$. After that, the armature current is again reverted to $i_{\mathrm{a}}$. Consequently, the flux linkage changes to $\Psi_{\text {a_min }}$. Then, the armature current is imposed at $i_{\mathrm{a}}$ while the armature flux linkage increases till the rotor position reaches the aligned rotor position $\mathrm{B}$ again.

The $(i-\Psi)$ - loop of the single-phase DCEFSM with this switching strategy is thus derived, shown in Fig. 6f. Similar to that explained in (5), the total area enclosed in this $(i-\Psi)$ loop BCEF indicates the converted mechanical energy 


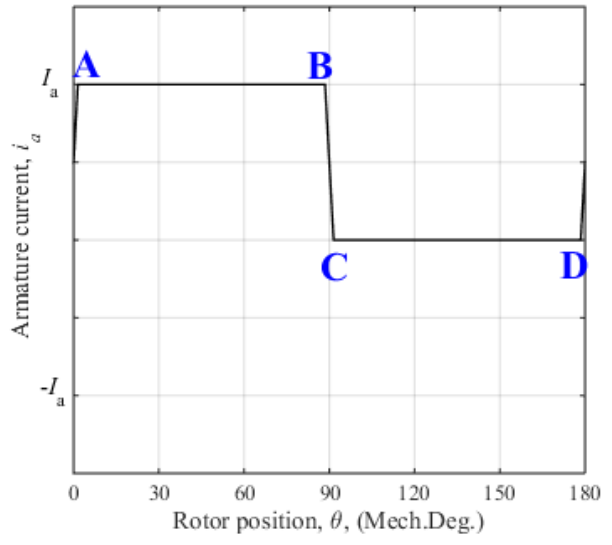

(a)

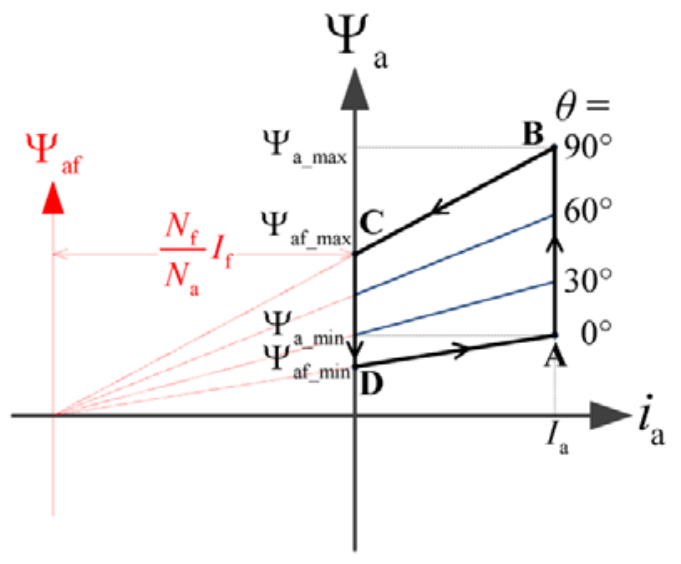

(b)

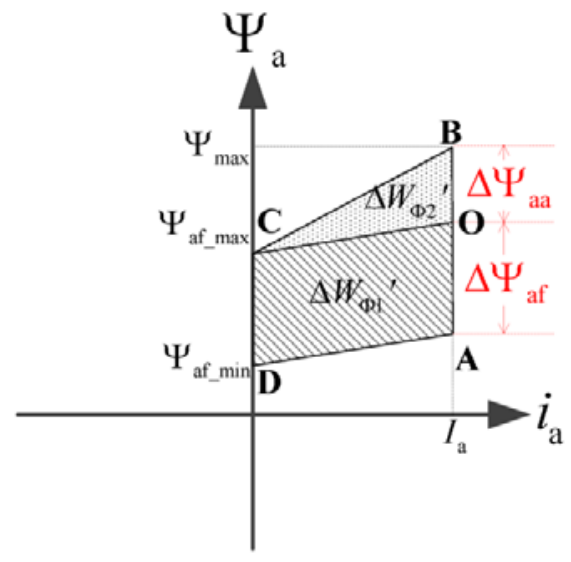

(c)

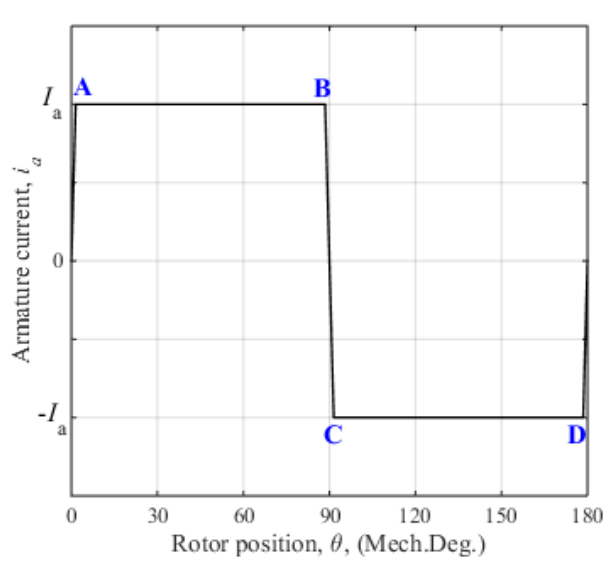

(d)

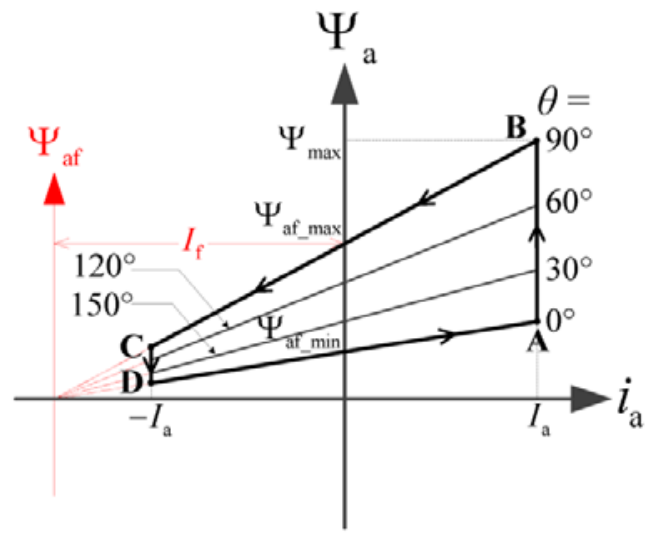

(e)

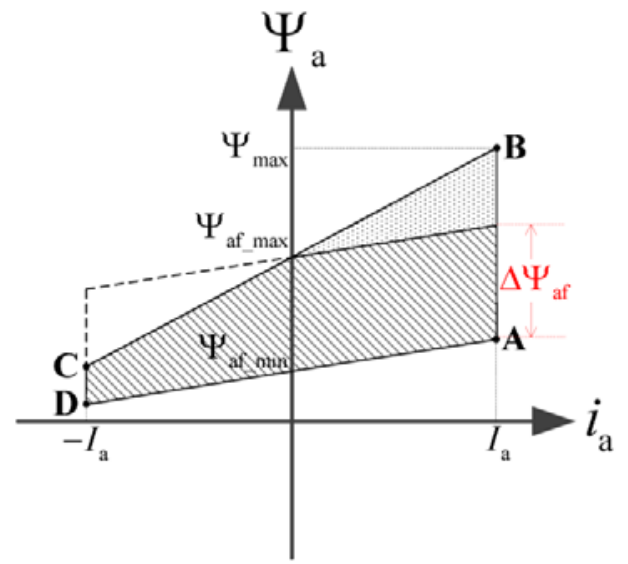

(f)

Figure 8: Energy/ co-energy of the single-phase DCEDSM with half-period current conduction and with full-period current conduction, respectively: a) idealized waveform of the armature current; b) energy/co-energy conversion process; c) current-flux linkage loop; d) idealized waveform of the armature current; e) energy/co-energy conversion process; e) current-flux linkage loop.

$w_{\text {mech, }}$ which is equal to the change of co-energy $\Delta W_{\Phi}^{\prime}$ in one electrical period using this switching strategy.From Fig. $6 f$ it can be seen that the length of the side FB is the difference between $\Psi_{a_{-} \max }$ and $\Psi_{a_{-} \min }$ :

$$
\psi_{a_{-} \max }-\psi_{a_{-} \min }=2 \psi_{a f_{-} \max }=2 M_{a f \_ \text {max }} I_{f} .
$$

Hence, for the single-phase DCEFSM using this switching strategy, the total area $\Delta W^{\prime}{ }_{\Phi}$ and the mean torque can be calculated as: 


$$
\begin{array}{r}
\Delta W_{\Phi}^{\prime}{ }_{\Phi}=2 M_{a f \_\max } I_{f} 2 I_{a}=4 M_{a f \_\max } I_{f} I_{a}, \\
\bar{T}=\frac{\Delta W_{\Phi}^{\prime}}{\pi}=\frac{4}{\pi} M_{a f \_\max } I_{f} I_{a} .
\end{array}
$$

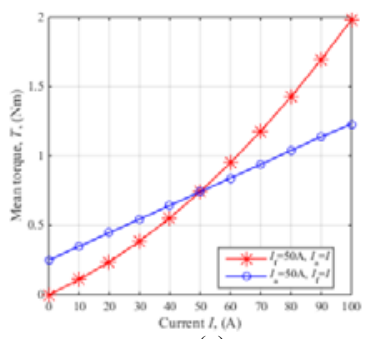

(a)

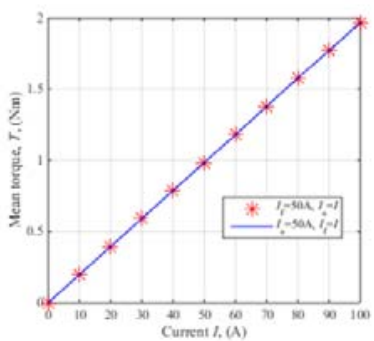

(c)

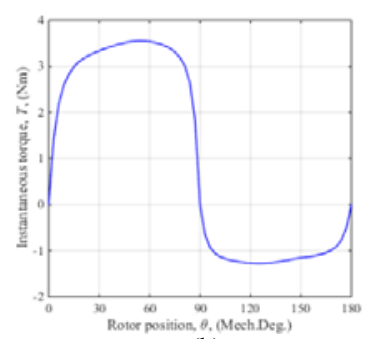

(b)

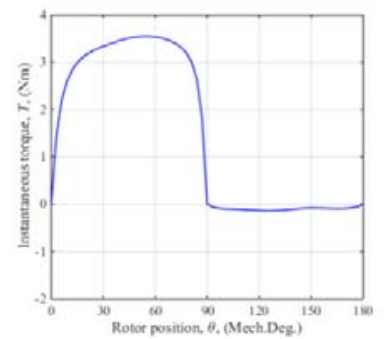

(d)
Figure 9: FEA results of the torque production in single-phase DC excited double-salient machine with half-period current conduction (S1) and fullperiod current conduction (S2): a) S1: mean torque vs. armature current / field current; b) S1: torque vs. rotor position $\left(I_{a}=I_{f}=50 \mathrm{~A}\right)$; c) S2: mean torque vs. armature current /field current; b) S2: torque vs. rotor position $\left(I_{a}=I_{f}=50 \mathrm{~A}\right)$.

While for a single-phase FSPMM using this switching strategy, the torque expression is:

$$
\bar{T}=\frac{4}{\pi} \Delta \psi_{m \_\max } I_{a} .
$$

The second item in (9) and (10) that is comparable to the reluctance torque of an SRM disappears in (15) and (16). The torque expression of the single-phase FSM with this full-period current conduction becomes similar to that of a DC machine or a non-salient synchronous machine.

The FEA results of the mean torque of a single-phase two-rotor DCEFSM with this full-period current conduction are presented in Fig. 7c. It can be seen that the relation between the mean torque and the peak value of the armature current, $i_{\mathrm{a}}$, is identical to that between the torque and the field current $i_{\mathrm{f}}$, both of which are linear. Thus, the torque expression resented in (15) is validated.

Figure $7 \mathrm{~d}$ shows the torque variation with respect to the rotor position when the field current equals the rms value of the armature current. In this case, the negative torque is eliminated. However, this does not mean that the switching strategy full-period current conduction always gives a higher torque than the half-period current conduction. By comparing (9) and (15) it can be found that the full-period current conduction is advantageous only when:

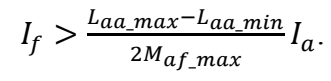

\section{ENERGY CONVERSION IN DOUBLE SALIENT MACHINES}

\section{A. Half-period current conduction}

In DSMs, the flux linkage created by permanent magnets or the field current is unipolar, hence with half-period current conduction the armature current does not need to revert. Figure 8a shows the idealized waveform of the armature current for a single-phase DSM using this switching strategy. The process of energy/co-energy conversion is presented in Fig. 8b. The red dashed lines present the relationship between the armature flux linkage created by the DC-field current and the equivalent current $\left(N_{f} / N_{a}\right) i_{f}$. The slope of each line corresponds to the selfinductance $L_{a a}$ with different rotor positions, as explained in Section IV. The lines inside ABCD show the additional flux linkage component created by the armature current, which are simply an extension to the dashed lines. The ( $i$ $\Psi)$-loop of this DSM is thus derived, shown in Fig. 8c.

The process of energy conversion in this machine is comparable to that in the single-phase FSM for half electrical period. When the rotor position changes from A: $\theta=0^{\circ}$ to B: $\theta=90^{\circ}$, the self- and mutual inductances $L_{\text {aa }}$ and $M_{\mathrm{af}}$ increase, hence the armature flux linkage increases when the armature current is imposed at $i_{\mathrm{a}}$. In this process the input electrical energy is partially converted to the energy stored in the magnetic field and partially to the mechanical energy of the rotor. When the rotor reaches the aligned position $\mathrm{B}$, both inductances reach their maximum values. To prevent the converted mechanical energy from being taken back to the electric circuit, the armature current is switched off. From $\mathrm{C}$ to $\mathrm{D}$, the armature flux linkage only contains the component created by the field current, which decreases with $M_{\mathrm{af}}$. At the point $\mathrm{D}$, the armature flux linkage reaches its minimum value, where another electrical period starts. Hence, for the DSM with half-period current conduction, the converted mechanical energy, $w_{\text {mech }}$, during an electrical period corresponds to the area enclosed in the $(i-\Psi)$-loops ABCD. This area can also be divided into two parts: a parallelogram (AOCD) and a triangle (OBC). The length of the side AO indicates the difference between the armature flux linkages created by the field current of the aligned and unaligned rotor positions, $\Delta \Psi_{a f}$. While, the length of the side OB indicates the difference between the armature flux linkages created by the armature current with the two rotor positions, $\Delta \Psi_{a}$. The converted mechanical energy, $w_{\text {mech }}$, can thus be calculated as:

$$
\begin{gathered}
w_{\text {mech }}=\Delta \psi_{a f} I_{a}+\frac{1}{2} \Delta \psi_{a a} I_{a}=\frac{N_{f}}{N_{a}}\left(L_{a a \_m a x}-\right. \\
\left.L_{a a \_m i n}\right) I_{a} I_{f}+\frac{1}{2}\left(L_{a a \_m a x}-L_{a a \_m i n}\right) I_{a}^{2}
\end{gathered}
$$

where $L_{\text {aa_max }}$ and $L_{\text {aa_min }}$ are the maximum and minimum self-inductance of the armature winding, when rotor teeth are fully aligned and misaligned with stator teeth, respectively. Hence, the mean torque of this single-phase DCEDSM with half-period current conduction can be expressed as: 


$$
\bar{T}=\frac{w_{\text {mech }}}{\pi}=\frac{N_{f}}{\pi N_{a}}\left(L_{\text {aa_max }}-L_{\text {aa_min }}\right) I_{a} I_{f}+\frac{1}{2 \pi}\left(L_{\text {aa_max }}-\right.
$$

For DSPMM, the excitation flux linkage, $\Psi_{a f}$, is denoted as $\Psi_{m}$, hence the torque expression of a single-phase FSPMM using this switching strategy is:

$$
\bar{T}=\frac{1}{\pi} \Delta \psi_{m} I_{a}+\frac{1}{2 \pi}\left(L_{a a_{-} \max }-L_{a a_{-} \min }\right) I_{a}^{2} .
$$

Similar to that is observed from (9) and (10), two torque components can also be found in (19) and (20): one that shows an analogue to the Lorentz torque and one to the reluctance torque. Furthermore, a negative torque is produced after the rotor crosses the aligned position due to the presence of the excitation field. Therefore, this switching strategy is also not optimal for the torque of DSMs.

The FEA results of the torque production in a singlephase DCEDSM with this half-period current conduction are presented in Fig. 9(a, b). It can be seen in Fig.9a that when the field current is constant, e.g. $i_{\mathrm{f}}=50 \mathrm{~A}$, the mean torque shows a second order relation with the peak value of the armature current, $i_{\mathrm{a}}$, while when the armature current is constant, the relation between the mean torque and the field current is fairly linear. Hence, the relation between the mean torque and the armature and field currents presented in (19) is validated.

\section{B Full-period current conduction}

Similar to that done for FSMs, for DSMs the negative reluctance /cogging torque can be reduced by reverting the armature current as soon as the rotor crosses the aligned position. The idealized waveform of the armature current using this switching strategy is shown in Fig. 8d. The process of energy/co-energy conversion with this switching strategy is shown in Fig. 8e. When the rotor reaches the aligned position B: $\theta=90^{\circ}$, the armature current changes from $i_{a}$ to $-i_{a}$ and is then imposed at this negative value till the rotor reaches the next unaligned position D: $\theta=180^{\circ}$. The $(i-\Psi)$ - loop of the single-phase DCEFSM with this switching strategy is shown in Fig. 8f. The total area enclosed in this $(i-\Psi)$-loop ABCD indicates the converted mechanical energy, $w_{\text {mech }}$, during an electrical period, which can be calculated as:

$$
w_{\text {mech }}=\Delta \psi_{a f} 2 I_{a} .
$$

For a DCEDSM:

$$
\begin{gathered}
\Delta \psi_{a f}=\left(\begin{array}{c}
\left(L_{a a \_m a x}-M_{a f \_m i n}\right) I_{f} \\
\left.L_{a a \_ \text {min }}\right) I_{f} .
\end{array}=\frac{N_{f}}{N_{a}}\left(L_{a a \_ \text {max }}-\right.\right. \\
\text { (22) }
\end{gathered}
$$

Hence, the mean torque can be expressed as:

$$
\bar{T}=\frac{w_{\text {mech }}}{\pi}=\frac{2 N_{f}}{\pi N_{a}}\left(L_{a a_{\_} \max }-L_{a a_{-} \min }\right) I_{a} I_{f} .
$$

While for a single-phase DSPMM, $\Delta \Psi_{a f}$ is denoted as $\Delta \Psi_{m}$. Thus, the torque expression is:

$$
\bar{T}=\frac{2}{\pi} \Delta \psi_{m} I_{a} .
$$

Therefore, with full-period current conduction the torque expressions of single-phase DSMs also become similar to that of a DC machine or non-salient synchronous machine.

The FEA results of the mean torque of a single-phase two-rotor DCEDSM with this full-period current conduction are presented in Fig.9c. It can be seen that the relation between the mean torque and the peak value of the armature current $i_{a}$ is identical to that between the torque and the field current $i_{f}$, both of which are linear. Thus, the torque expression presented in (23) is validated.

Figure 9d shows the torque variation with respect to the rotor position when the field current equals the rms value of the armature current. In this case, the negative torque is eliminated. However, this does not mean that the switching strategy full-period current conduction always gives a higher torque than the half-period current conduction. By comparing (19) and (23) it can be found that the full-period current conduction is advantageous only when:

$$
N_{a} I_{a}<2 N_{f} I_{f}
$$

\section{NATURE OF TORQUE PRODUCTION}

From previous sections it is understood that with halfperiod current conduction, the torque expression of HEVRMs presents a similarity to that of salient-pole WFSMs or PMSMs, while with full-period current conduction, this torque expression of HEVRMs is comparable to that of DCM and non-salient WFSM and PMSM.

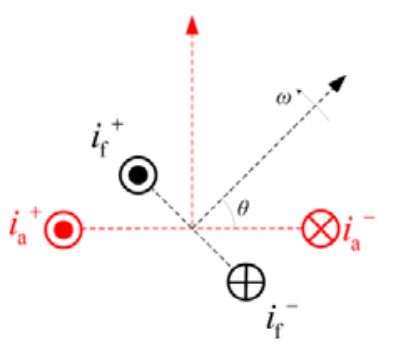

(a)

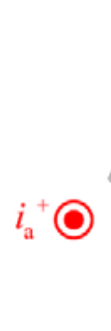

$i_{\mathrm{f}}$

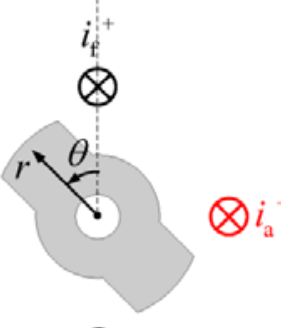

(b)
Figure 10: Cross-sections of a single-phase a) non-salient wound-field synchronous machine (WFSM) and b) DC-excited flux-switching machine (DCEFSM).

In these both equations, a torque component, proportional to the product of the armature current and the excitation field, can be found. For DCMs, WFSMs and PMSMs, this component is equivalent to the Lorentz torque exerted on a virtual coil placed in the airgap of these machines while carrying the armature current. However, this equivalence is invalid for HEVRMs. In this class of machines, all magnetic excitation sources such as the armature winding, field winding, or permanent magnets are static (located at the stator). Hence, although there is a Lorentz force exerted on the armature winding, it is not the force that tends to rotate the rotor. The different nature of torque production in 
HEVRMs can be observed by comparing a single-phase WFSM and a single-phase DCEFSM, as shown in Fig. 10.

The WFSM is ironless. In other words, the stator of the WFSM is simply an armature coil, while the rotor is a field coil. The stator of the DCEFSM is also ironless, thus consisting of only an armature coil and a field coil. The rotor of the DCEFSM is a ferromagnetic body with two salient teeth. Using FEA, the electromagnetic torques exerted on the armature coil and the rotor of both machines with different armature and field currents are calculated, shown in Fig.11 and Fig.12, respectively. From Fig.11a it can be seen that in the WFSM, the instantaneous torque exerted on the rotor is always equal and opposite to the instantaneous torque exerted on the armature coil. Hence, in this machine the torque production is resulting from the action and reaction of the Lorentz force between the two magnetic sources.

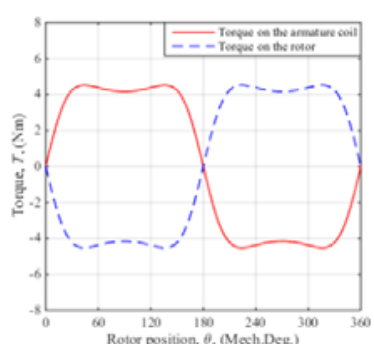

(a)

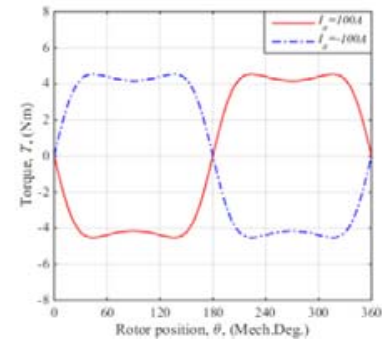

(b)
Figure 11: FEA results of the torque production in single-phase non-salient wound-field synchronous machine: a) torque on the armature coil vs. torque on the rotor; b) WFSM: torque produced by positive and negative armature currents.

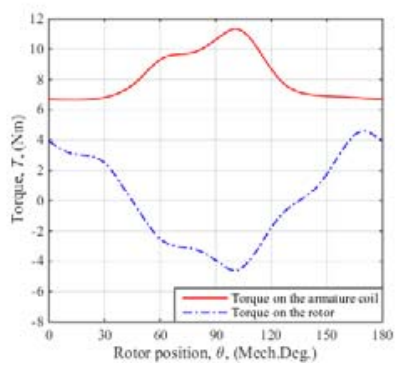

(a)

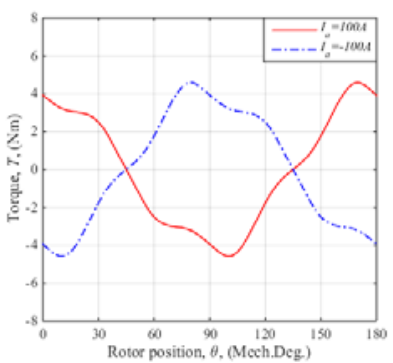

(b)
Figure 12: FEA results of the torque production in single-phase DCexcited flux-switching machine: a) torque on the armature coil vs. torque on the rotor; b) WFSM: torque produced by positive and negative armature currents.

However, this action-reaction relationship cannot be found between the two torques of the DCEFSM shown in Fig.12a. Furthermore, according to the nature of Lorentz force the generated force is equal and opposite when the current is reverted. This is true for the WFSM at instant of time, as shown in Fig. 11b. However, for the FSPMM, this is only valid for the mean torque within an electrical period, while the instantaneous torques vary in a different manner, as shown in Fig. 12 b.

These results indicate that the torque production of HEVRMs is not resulting from the Lorentz force exerted on the armature coil. In these machines, the nature of the torque production is the interaction between a synthesized magnetic field resulting from various static magnetic excitations sources, such as armature windings, field windings, and permanent magnets, and a salient and movable ferromagnetic body, i.e. the rotor.

\section{CONCLUSIONS}

In this paper, a study on the energy conversion and the consequent torque production mechanism in hybrid excited variable reluctance machines (HEVRMs) is presented. The derived torque expressions of single-phase HEVRMs with different switching strategies show a similarity to that of DC machines (DCMs), wound-field synchronous machines (WFSMs), or permanent-magnet synchronous machines (PMSM).

Nevertheless, distinct from the Lorentz torque generated in these three types of machines, the torque generated in HEVRMs is a synthesis of reluctance/cogging torques resulting from the interaction between multiple magnetic excitation sources in the stator and the salient rotor. In HEVRMs, the magnetic excitation sources such as permanent magnets and field windings are placed in the stator. Thus, compared to DCMs, WFSMs, and PMSMs, the most visible advantage of HEVRMs is that they allow a robust rotor structure similar to that of SRMs.

In addition, permanent magnets or field windings can be more effectively cooled when they are in the stator, suggesting a high thermal loading capability of this type of machines [23]. However, to include these magnetic excitation sources in the stator, the space for armature winding is reduced, thus reducing the electrical loading and limiting the torque density. Compared to SRMs, the premagnetization in HEVRMs increases the power factor, hence decreases the volt-ampere (VA) requirement of the power supply [24][11]. Furthermore, In certain three-phase HEVRMs, the waveform of phase flux-linkage presents a fairly sinusoidal characteristic. These HEVRMs can be driven and controlled in a similar manner to conventional three-phase brushless AC machines and usually produce lower torque ripples than SRMs.

\section{REFERENCES}

1. J.H. Walker. "High frequency alternators". Journal of the Institution of Electrical Engineers-Part II: Power Engineering, 93(31):67-80, 1946.

2. S. E. Rauch, L.J. Johnson. "Design principles of flux-switch alternators", [includes discussion]. Power Apparatus and Systems, Part III. Trans. of the American Institute of Electrical Engineers, 74(3), Jan 1955.

3. T. Raminosoa, C. Gerada. "A comparative study of permanent magnet synchronous and permanent magnet - flux switching machines for fault tolerant drive systems". In Energy Conversion Congress and Exposition (ECCE), 2010 IEEE, pages 2471-2478, 2010.

4. Meng-Jia Jin, Can-Fei Wang, Jian-Xin Shen, Bing Xia. "A modular permanent-magnet flux-switching linear machine with fault-tolerant capability". 45(8):3179-3186, 2009.

5. Z.Q. Zhu, J.T. Chen, Y. Pang, D. Howe, S. Iwasaki, R.P. Deodhar. "Analysis of a novel multi-tooth flux-switching pm brushless AC machine for high torque direct-drive applications". 44(11):4313-4316, 2008.

6. D.C.J. Krop, L. Encica, E.A. Lomonova. "Analysis of a novel double sided flux switching linear motor topology". In Electrical Machines(ICEM), 2010 19th International Conference on, pp. 1-5, 2010.

7. J.T. Chen, Z.Q. Zhu, S. Iwasaki, R.P. Deodhar. "A novel e-core switched-flux PM brushless AC machine”. 47(3):1273-1282, 2011.

8. Z.Q. Zhu. "Switched flux permanent magnet machines | innovation continues". In Electrical Machines and Systems (ICEMS), 2011 International Conference on, pages 1-10, 2011. 
9. R.P. Deodhar, S. Andersson, I. Boldea, T.J.E. Miller. "The flux reversal machine: a new brushless doubly-salient permanent-magnet machine".33(4):925-934, 1997.

10. C. Wang, S.A. Nasar, I. Boldea. "Three-phase flux reversal machine (FRM)". IEE Proceedings-Electric Power Applications, 146(2):139-146, 1999.

11. D.A. Philips. "Switched reluctance drives: new aspects". Industry Applications, IEEE Trans. on, 5(4):454- 458, 1990.

12. F. Liang, Yuefeng Liao, T.A. Lipo. "A new variable reluctance motor utilizing an auxiliary commutation winding". Industry Applications, IEEE Trans. on, 30(2):423- 432, 1994.

13. Yuefeng Liao, F. Liang, T.A. Lipo. "A novel permanent magnet motor with doubly salient structure". Industry Applications, IEEE Trans. on, 31(5):1069-1078, Sep. 1995.

14. Yue Li, J.D. Lloyd, G.E. Horst. "Switched reluctance motor with dcassisted excitation". $31^{\text {st }}$ IAS Annual Meeting, IAS '96, IEEE, vol. 2, pp. 801-807, Oct. 1996.

15. Hongsik Hwang, Jin Hur, Cheewoo Lee. "Novel permanent-magnet assisted switched reluctance motor (i): Concept, design, and analysis". In Electrical Machines and Systems (ICEMS) Int. Conf. on, pp. 602-608, 2013.

16. Jeongwon Jeong, Jin Her, and Cheewoo Lee. "Novel permanentmagnetassisted switched reluctance motor (ii): Concept, design, and analysis". In Electrical Machines and Systems (ICEMS) Int. Conf. on, pp. 609-614, 2013.

17. X. Liu, Z.Q. Zhu. "Electromagnetic performance of novel variable flux-reluctance machines with DC-field coil in stator". 49(6):3020-3028, 2013.

18. C. Pollock, M. Wallace. "The flux switching motor, a de motor without magnets or brushes". In Industry Applications Conference, 34 ${ }^{\text {th }}$ IAS Annual Meeting. Conference Record of the IEEE, vol. 3, pp. 1980-1987, 1999.

19. E. Ilhan, M. F. J. Kremers, E. T. Motoasca, J. J H. Paulides, E. A. Lomonova. "Sensitivity analysis for phase inductances in flux-switching PM machines". In Electrical Machines (ICEM), 20th International Conference on, pp.763-768, Sept. 2012.

20. E. Ilhan, T. E. Motoasca, J. J. H. Paulides, E. A. Lomonova. "Energy conversion loops for flux-switching PM machine analysis". ETASR: Engineering, Technology and Applied Science Research, 2(5):285-290, 2012.

21. Wei Hua, Ming Cheng, Z.Q. Zhu, and D. Howe. "Design of fluxswitching permanent magnet machine considering the limitation of inverter and flux weakening capability". In Industry Applications Conference, 2006. 41 ${ }^{\text {st }}$ IAS Annual Meeting. Conference Record of the 2006 IEEE, vol. 5, pp. 2403-2410, Oct. 2006.

22. X. Liu, Z.Q. Zhu. "Influence of rotor pole number on electromagnetic performance of novel variable flux reluctance machine with DC-field coil in stator". In Power Electronics and Motion Control Conference (IPEMC), 7th International, vol. 2, pp. 1108-1115, 2012.

23. Y. Tang, T. E. Motoasca, J. J. H. Paulides, E. A. Lomonova. "Comparison of flux-switching machines and permanent magnet synchronous machines in an in-wheel traction application”. COMPEL, 32(1):153-165, 2013.

24. T.J.E. Miller. "Converter volt-ampere requirements of the switched reluctance motor drive”. IA-21(5):1136-1144, 1985. 